\title{
Evaluation of Current Code Criteria Selecting Ground Motions for Dynamic Analysis
}

\author{
An accurate algorithm for selecting ground motions
}

\author{
Seongjin HA \\ Architectural Engineering \\ Hanyang University \\ Seoul, Republic of Korea \\ e-mail: hasz2233@gmail.com
}

\author{
Miyoung PARK \\ Architectural Engineering \\ Hanyang University \\ Seoul, Republic of Korea \\ e-mail: miyeong1217@gmail.com
}

\author{
Sangwhan HAN \\ Architectural Engineering \\ Hanyang University \\ Seoul, Republic of Korea \\ e-mail: swhan@hanyang.ac.kr
}

\begin{abstract}
For estimating the seismic demand of buildings, most seismic design provisions permit conducting linear and nonlinear response history analysis. In order to obtain reliable results from response history analyses, a proper selection of input ground motions is required. In this study, an accurate algorithm for selecting and scaling ground motions is proposed, which satisfies the ASCE 7-10 criteria. In the proposed algorithm, a desired number of ground motions are sequentially scaled and selected from a ground motion library without iterations.
\end{abstract}

Keywords-seismic design provision; reponse history analysis; ground motion; selection; algorihtm

\section{INTRODUCTION}

Most seismic design provisions permit three analysis procedures: equivalent lateral force analysis, modal response spectrum analysis, and linear and nonlinear response history analyses (RHA) [1]. The equivalent lateral force analysis is permitted only for regular structures assigned as low seismic design category, with heights within a specific height limit. If the equivalent lateral force analysis is not permitted, modal response spectrum analyses and response history analyses shall be used. Among three analysis procedures, RHA can produce the most accurate results. In order to obtain reliable results using RHA, accurate analytical models and adequate input ground motions should be used. According to ASCE 710 [1], appropriate ground motions for RHA shall be obtained from records of events having magnitudes, fault distance, and source mechanisms that are consistent with those that control the maximum considered earthquake at a site. If appropriate recorded ground motions are not available, simulated ground motions can be used.

According to ASCE 7-10 [1], the target response spectrum can be a design response spectrum or uniform hazard response spectrum (UHRS) obtained from probabilistic seismic hazard analysis (PSHA).

Recently, many methods have been developed for selecting input ground motions. Naeim et al. [2] proposed procedures for selecting and scaling ground motions that match the UHS. However, such procedures cannot be used for selecting ground motions whose response spectra match a target response spectrum mean and variance. Kottke and Rathje [3] developed a semi-automated procedure for selecting and scaling ground motions that match the target response spectrum mean and variance. This procedure, however, does not easily scale to work with large ground motion libraries, cannot be used for the selection of unscaled ground motions.

Alternatively, Monte Carlo simulation-based methods [45] were developed to select ground motions that accurately match the target response spectrum. In the procedure, to refine their selection, multiple sets of response spectra are generated using these methods instead of a single set of ground motions. Individual sets of ground motions are then selected for each set of response spectra. Among the sets of selected ground motions, a set with response spectra that best match the target response spectrum is the set to be finally selected. However, Monte Carlo Simulation based-methods are complex, and require expensive and limited programming languages such as MATLAB that contain built-in subroutines to generate multiple response spectra based on information about the target response spectrum mean, variance and covariance. Furthermore, a unique set of ground motions cannot be obtained using a simulation basedselection method since subroutines require random number generation, which may affect the results of RHA for a structure.

In this study, an accurate and computationally efficient algorithm for selecting ground motions satisfying ASCE 710 [1] criteria. The proposed procedure can be used for 
selecting both scaled and unscaled ground motions. The efficiency and accuracy of the proposed method are verified using numerical examples.

\section{ASCE 7-10 CRITERA FOR SELECTING INPUT GROUND MOTIONS}

According to ASCE 7-10 [1], At least three recorded or simulated ground motions are required as input ground motions for RHA.

For two-dimensional analyses, ground motions shall be scaled in the period range from $0.2 T_{n}-1.5 T_{n}$, such that the average value of their $5 \%$ damped response spectra is not less than the design (target) response spectrum, where $T_{n}$ is the fundamental period of a structure. For three-dimensional analyses, ground motions consist of pairs of appropriate horizontal ground motion components. For each pair of horizontal ground motion components, a square root of the sum of the squares (SRSS) spectrum shall be constructed by taking the SRSS of the $5 \%$ damped response spectra for the scaled components where an identical scale factor is applied to both components of a pair. Each pair of motions shall be scaled in the period range from $0.2 T_{n}-1.5 T_{n}$ so that the average of the SRSS spectra does not fall below the target response spectrum. If fewer than seven ground motions are used in the analyses, design response demands shall be taken as the maximum values of response demands over all ground motions. If at least seven ground motions are used, the design response demands are permitted to be taken as the average value of response demands over all ground motions.

\section{PROPOSED ALGORITHM}

\section{A. Target Response Spectrum and Ground Motions Library}

In order to construct a target response spectrum, the design response spectrum at Los Angeles (latitude: $34.05 \mathrm{~N}$, longitude: $118.24 \mathrm{~W}$ ) is calculated according to ASCE 7-10 [1]. Fig.1 shows the target response spectrum used in this study.

For conduction ground motions library, 7102 horizontal ground motions are collected from the NGA database.

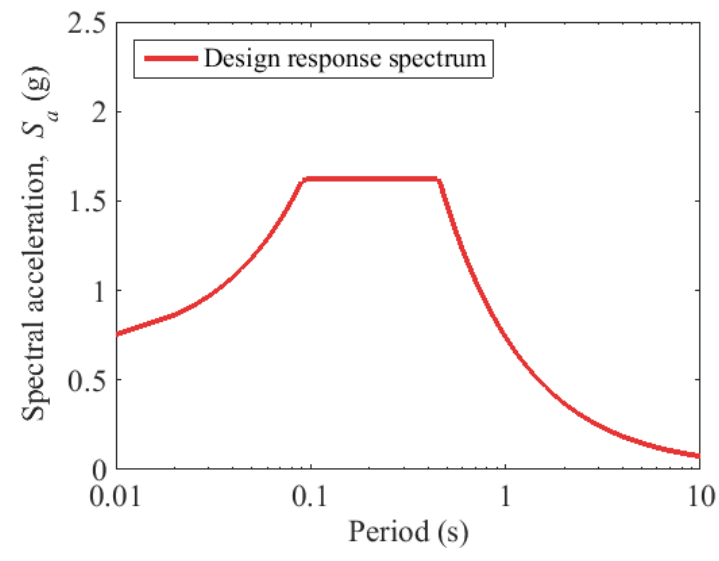

Figure 1. Target response spectrum

\section{B. Scaling Ground Motoin in a Library}

In this study, an accurate and computationally efficient algorithm is proposed for selecting ground motions that satisfy the ASCE 7-10 [1] criteria.

First, all ground motions in a library are scaled to match a target response spectrum. Scaling the ground motions is permitted in ASCE 7-10 [1]. However, if it is not allowed to scale the ground motions, the scaling process can be skipped in the proposed algorithm.

A scaling factor $(s)$ for individual ground motions can be easily determined without iterations using (1) and (2) [5]:

$$
\begin{gathered}
\mu_{\Delta}=\frac{1}{n_{p}} \sum_{i=1}^{n_{p}} \Delta_{i}=\frac{1}{n_{p}} \sum_{i=1}^{n_{p}}\left[\ln S_{a}^{\text {target }}\left(T_{i}\right)-\ln S_{a}\left(T_{i}\right)\right] \\
s=\exp \left(\mu_{\Delta}\right)
\end{gathered}
$$

where $\ln S_{a}^{\text {target }}\left(T_{i}\right)$ and $\ln S_{a}\left(T_{i}\right)$ are the logarithmic $5 \%$ damped target and sample response spectra at period $T_{i}$, respectively, and $n_{p}$ is the number of periods in a given period range. In this study, a period range between $0.2 T_{n}$ $1.5 T_{n}$ is used according to Section 16.1.3.1 of ASCE 7-10 [1].

Fig.2 shows the response spectra of a ground motion before and after scaling. The fundamental period of a structure is assumed as $1.0 \mathrm{~s}$ so that a period range from $0.2 \mathrm{~s}$ to $1.5 \mathrm{~s}$ is used for calculating a scaling factor.

\section{Selecting Fewer than Seven Ground Motions}

According to ASCE 7-10 [1], if fewer than seven but more than two ground motions $\left(3 \leq n_{g}<7\right)$ are used in analyses, the seismic response demands should be taken as the maximum values of the response demands over all ground motions.

In the proposed procedure, a desired number of ground motions are sequentially selected from scaled ground motions in a library that best match a target spectrum.

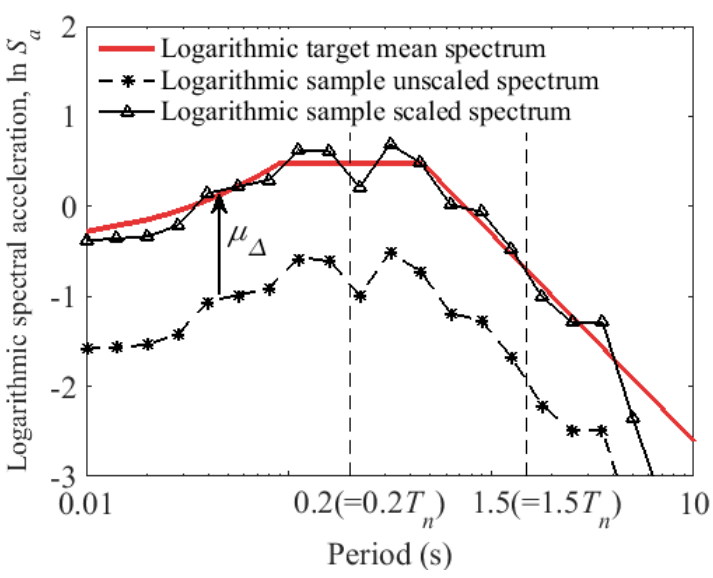

Figure 2. Scaling of a ground motions in the library 
The fitness between a target and individual response spectra is measured using the sum of squared error (SSE) calculated using (3).

$$
S S E=\sum_{i=1}^{n_{p}}\left[\ln S_{a}^{\text {target }}\left(T_{i}\right)-\ln s \times S_{a}\left(T_{i}\right)\right]^{2}
$$

where $\ln S_{a}^{\text {target }}\left(T_{i}\right)$ and $\ln s \times S_{a}\left(T_{i}\right)$ are the logarithmic target and scaled sample response spectra at a period $T_{i}$, respectively. A ground motion with the smallest $S S E$ indicates that the ground motion best matches the target response spectrum among scaled ground motions in a library.

Fig. 3 shows the response spectra of the three ground motions that have the smallest SSE among scaled ground motions is the library. For calculating SSE, a period range from $0.2 T_{n}$ to $1.5 T_{n}$ is used with consideration of a structure having $T_{n}=1.0 \mathrm{~s}$. As seen in Fig. 3, the response spectra of the selected ground motions disperse narrowly and also accurately match with a target response spectrum.

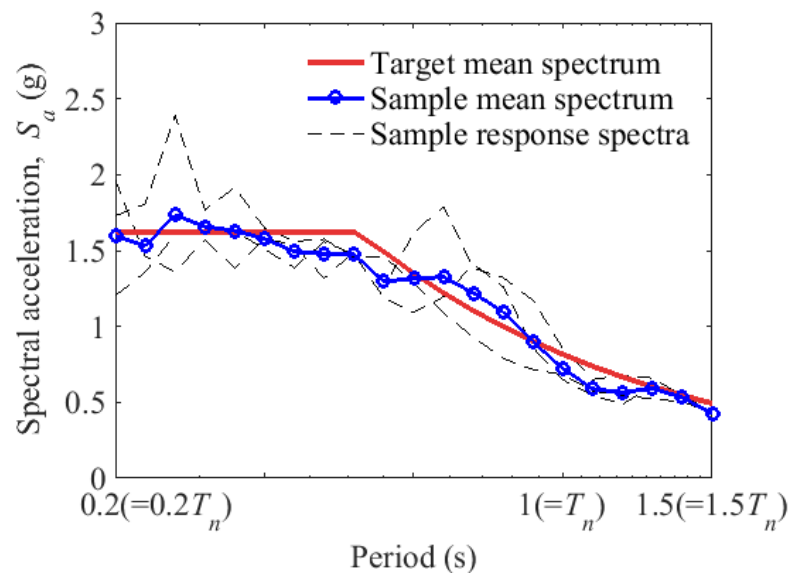

Figure 3. Selected ground motions for $n_{g}=3$

\section{Selecting at Least Seven Ground Motions}

If at least seven ground motions are used in analyses, ground motions are sequentially selected from scaled ground motions in a library until a desired number of ground motions are selected. The fitness between target and mean response spectra is measured with a period ranging from $0.2 T_{n}$ to $1.5 T_{n}$. The following are the steps for selecting ground motions.

The first ground motion is selected from a library, which has the smallest $\operatorname{SSE}[(3)]$ among scaled ground motions in the library. The first step is exactly the same as that previously used for selecting fewer than seven ground motions. After selecting the first ground motion, another ground motion is selected, which makes the mean response spectrum of selected ground motions a best match for the target response spectrum. This process is repeated until a desired number $\left(n_{g}\right)$ of ground motions are selected.

To avoid selecting the same ground motion that was selected previously when selecting the $k^{\text {th }}$ ground motion, $k-1$ ground motions selected in previous iterations are removed from the library. Therefore, the $k^{\text {th }}$ ground motion is selected from $n_{L}-(k-1)$ ground motions remaining in the library, where $n_{L}$ is the original number of ground motions in the library. The fitness between target and mean response spectra is measured using $S S E_{S}$ calculated using (4) and (5):

$$
\begin{gathered}
S S E_{S}=\sum_{i=1}^{n_{p}}\left[\ln S_{a}^{\text {target }}\left(T_{i}\right)-\mu_{\ln S_{a}\left(T_{i}\right)}\right]^{2} \\
\mu_{\ln S_{a}\left(T_{i}\right)}=\frac{1}{k} \sum_{j=1}^{k}\left[\ln s_{j} \times S_{a j}\left(T_{i}\right)\right]
\end{gathered}
$$

where $\ln s_{j} \times S_{a j}\left(T_{i}\right)$ is the $j^{\text {th }}$ ground motion $(j \leq k)$ selected from the scaled ground motions in a library. To select the $k^{\text {th }}$ ground motion properly $(k \geq 2), S S E_{S}$ is calculated using (4) with the previously selected $k-1$ ground motions and one candidate ground motion in a library with $n_{L}-(k-1)$ scaled ground motions. The ground motion producing the smallest $S S E_{S}$ is the one to be selected as the $k^{\text {th }}$ ground motion.

Fig. 4 shows the response spectra of seven ground motions selected using the proposed procedure from a library with 7102 scaled ground motions. The fundamental period of a structure is assumed to be $1 \mathrm{~s}$ so that the period range for calculating $S S E_{S}$ [(4)] is from $0.2 \mathrm{~s}\left(0.2 T_{n}\right)$ to $1.5 \mathrm{~s}\left(1.5 T_{n}\right)$. As shown in Fig.4, ground motions selected from the scaled ground motions in a library using the proposed procedure have a mean response spectrum that accurately match a target response spectrum and individual response spectra with small dispersion.

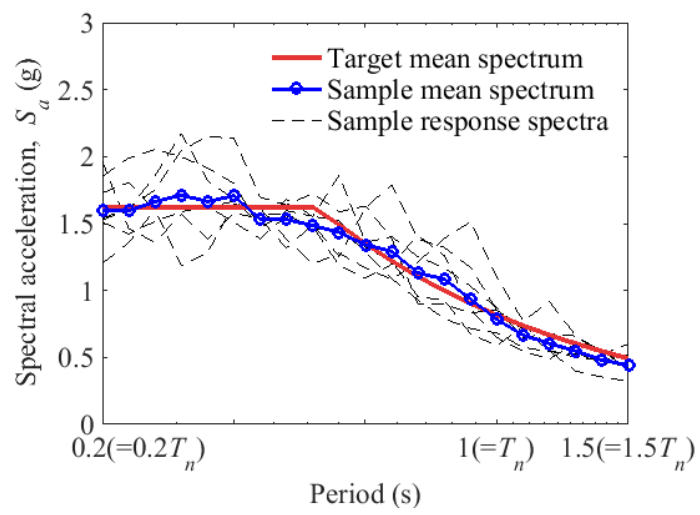

Figure 4. Selected ground motions for $n_{g}=7$ 


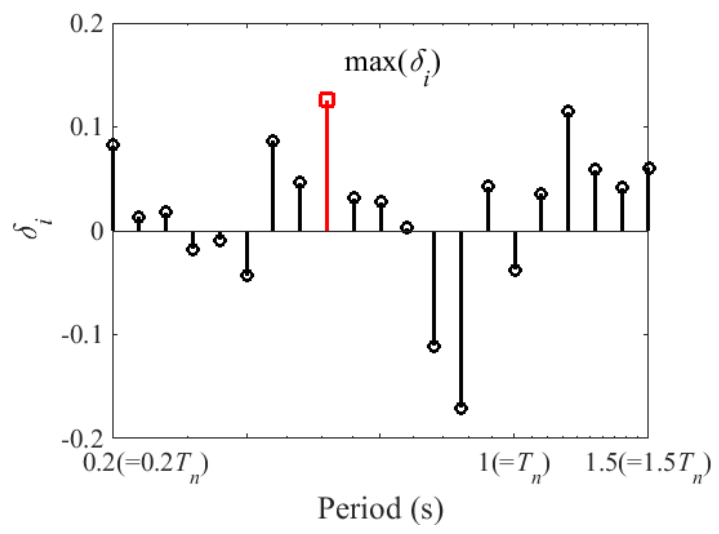

Figure 5. Finding re-scaling factor

\section{E. Rescaling Ground Motions}

According to Section 16.1.3.1 of ASCE 7-10 [1], the mean response spectrum of selected ground motions should be larger than a target response spectrum with a specific period range. Therefore, ground motions previously selected using the proposed procedure should be re-scaled to satisfy the ASCE 7-10 [1] criteria.

For determining re-scaling factors, the distance $\left(\delta_{i}\right)$ between the target and mean response spectra at period $T_{i}$ is calculated using (6).

$$
\delta_{i}=\ln S_{a}^{\mathrm{target}}\left(T_{i}\right)-\mu_{\ln S_{a}}\left(T_{i}\right)
$$

where $\mu_{\ln S_{a}}\left(T_{i}\right)$ is the mean logarithmic 5\% damped response spectrum of selected ground motions at period $T_{i}$. The maximum positive $\delta_{i}\left[\max \left(\delta_{i}\right)\right]$ within a given period range becomes a re-scaling factor. If $\delta_{i}$ is negative in a given period range, the selected ground motions need not be re-scaled. Otherwise, ground motions are rescaled with $\max \left(\delta_{i}\right)$. Therefore, the final scaling factor $\left(s_{k}^{*}\right)$ for individual selected ground motions is calculated using (7).

$$
\ln s_{k}^{*}=\left(\ln s_{k}\right)+\max \left(\delta_{i}\right) \quad\left(k=1 \sim n_{g}\right)
$$

where $s_{k}$ is the scaling factor that was already applied to ground motions in a library, as explained in the previous section.

Fig.5 shows $\delta_{i}$ and the maximum value of positive $\delta_{i}$ (rescaling factor). Fig. 6 shows the target response spectrum and mean response spectrum of rescaled ground motions.

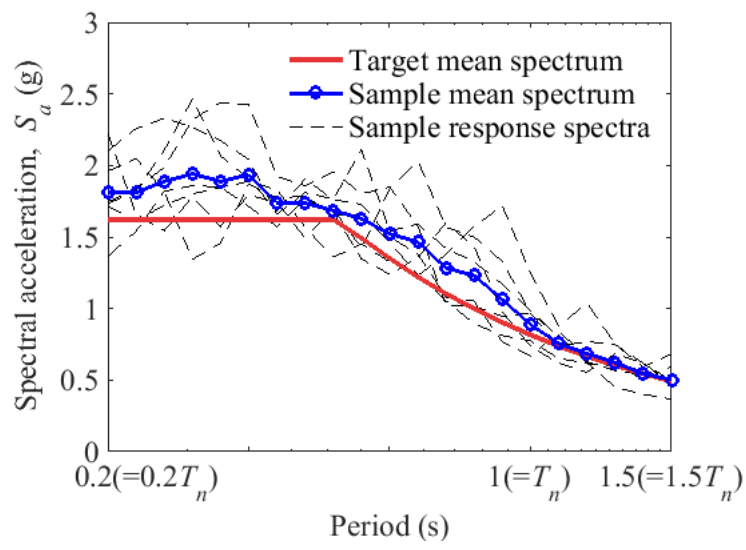

Figure 6. Target and rescaled response spectra

\section{CONCLUSION}

In this study, an efficient and accurate ground motion selection algorithm was proposed, which satisfied the ASCE 7-10 [1] selection criteria. For computational efficiency, a desired number of ground motions are sequentially selected from a library, using the proposed algorithm without considering all possible combinations of ground motions in a library. It was shown that ground motions selected using the proposed algorithm accurately matched a target response spectrum with a small variance.

\section{ACKNOWLEDGMENT}

Authors would like to acknowledge the financial supports provided by the National Research Foundation of Korea (No. 2014R1A2A1A11049488).

\section{REFERENCES}

[1] ASCE, "Minimum design loads for buildings and other structures," American Society of Civil Engineers, Reston, VA, 2010.

[2] F. Naeim, A. Alimoradi and S. Pezeshk, "Selection and scaling of ground motion time histories for structural design using genetic algorithms," Earthq. Spectra, vol. 20, no. 2, pp. 413-426, May 2004.

[3] A. R. Kottke and E. M. Rathje, "A semi-automated procedure for selecting and scaling recorded earthquake motions for dynamic analysis," Earthq. Spectra, vol. 24, no. 4, pp. 911-932, November 2008 .

[4] N. Jayaram, T. Lin, and J. W. Baker, "A computationally efficient ground-motion selection algorithm for matching a target response spectrum mean and variance," Earthq. Spectra, vol. 27, no. 3, pp. 797815, August 2011.

[5] S. W. Han and S. W. Seok, "Efficient procedure for selecting and scaling ground motions for response history analysis," J. Eatthquake. Eng, vol. 140, no. 1, January 2014. 